\title{
Magnetohydrodynamic Blood Flow in a Cylindrical Tube with Magnetic Particles: A Time Fractional Model
}

\author{
Farhad Ali $(\mathbb{D}$, Samina Majeed $\mathbb{D}$, and Anees Imtiaz \\ Department of Mathematics, City University of Science and Information Technology, Peshawar 25000, Pakistan \\ Correspondence should be addressed to Anees Imtiaz; anees.imtiaz@cusit.edu.pk
}

Received 22 December 2020; Revised 6 April 2021; Accepted 22 June 2021; Published 9 July 2021

Academic Editor: Efstratios Tzirtzilakis

Copyright (c) 2021 Farhad Ali et al. This is an open access article distributed under the Creative Commons Attribution License, which permits unrestricted use, distribution, and reproduction in any medium, provided the original work is properly cited.

\begin{abstract}
The present work theoretically investigates the natural convection blood flow as a Brinkman-type fluid with uniformly distributed magnetic particles in a circular cylindrical tube with the applied external magnetic field. The classical model for the blood flow is generalized by using the definition of Caputo time-fractional derivative. The exact solutions are obtained by using the Laplace and Henkel transforms. Unlike the classical model, the obtained general results are expressed in the form of "Lorenzo and Hartley's" and "Robotnov and Hartley's" functions. Graphs are plotted to show the effects of different parameters on the blood flow. Furthermore, the velocity and temperature distributions are discussed in terms of memory. The effect of fractional parameter $\alpha$ for a long and short time has also been observed. It is noticed that blood velocity can be controlled using the fractional parameter. It is also found that, for $\tau>0$, fluid and particles motion increased, and reverse behavior is observed for $\tau<0$. It has been noticed that increasing values of particle mass parameter $P_{m}$ and magnetic parameter $M$ slow down the motion of blood and magnetic particles. These results are helpful for effective drug delivery and regulating blood flow.
\end{abstract}

\section{Introduction}

Biomagnetic fluid dynamics (BFD) studies the magnetic effects on biofluids. BFD is a new area of attraction for researchers [1-3]. This new field has many applications in biomedical and engineering [4-7]. Blood is one of the essential biofluids, which is also biomagnetic [8-10]. Since many diseases, including cancer, there is a need to enhance the therapy methods which are less harmful and low cost. Therefore, scientists have made successful use of magnetic particles for this purpose, for example, hyperthermia where magnetic particles are transferred to the cancer cells and heated by the use of an external magnetic field. This helps to destroy the tumor cells without harming the normal tissues [11]. Magnetic particles are utilized in MRI, which is used for diagnostics of tumor cells [12]. Similarly, the use of magnetic particles is helpful in drug transport and bioseparation [13]. Due to wide applications of magnetic particles for the diagnostic and treatment of diseased cells, many researchers have developed mathematical models to observe the effects of magnetic particles in the blood. Tzirtzilakis [14] observed
Newtonian fluid's flow behavior in a rectangular duct under magnetic field application. Sharma et al. [9] studied the transverse magnetic field's impact on blood flow containing magnetic particles in a cylindrical tube. Ghasemi et al. [15] analyzed the two-phase flow of blood with uniformly distributed nanoparticles through arteries in the existence of the magnetic field. The $2 \mathrm{D}$ flow of blood through a porous artery with stenosis is examined by Ellahi et al. [16]. Bhatti et al. [17] examined the MHD flow of blood containing microscopic size metallic particles in a hollow cylinder. Variation in blood flow by using radiation in a small magnetized vessel is discussed by Sinha and Shit [18]. Khan et al. [19] investigated the magnetic field and heat transfer effects in Casson fluid flow. Their observation reported the reduction of fluid flow due to the increase in magnetic parameter. Gul et al. [20] analytically and numerically analyzed Casson blood flow with carbon nanotubes considering Marangoni convection and magnetic effects.

The joint applications of MHD and natural convection in non-Newtonian fluids have attracted many researchers due to vast applications in the real world, from industries to 
biological sciences [21, 22]. Fluid motion due to natural sources, i.e., buoyancy forces, is known as free convection or natural convection. Buoyancy forces arise because of the difference in densities. Rahbari et al. [23] investigated analytically and numerically the influence of MHD and natural convection fluid flow in a parallel plate channel. The influence of free convection heat transfer on the velocity of blood in a vessel is reported by Parkash and Ogulu [24]. Akbar [25] worked on the effects of mixed convection on blood flow in a stenosed artery.

In the present work, blood is taken as a Brinkman-type fluid. Brinkman-type fluid is a special kind of viscous fluid derived from the flow past on a high permeable medium [26-28]. Brinkman gave the idea of calculation of viscous forces which are exerted by fluid [29]. Ali et al. [30], with the help of Laplace transform, obtained the exact solutions of the Brinkman-type fluid model. The exact solution for Brinkman-type fluid with the help of Fourier sine transform is obtained by Fetecau et al. [31]. Anwar et al. [32] investigated Brinkman-type fluid model to inspect the enhancement of heat transfer due to iron oxide nanoparticles. They considered water and kerosene oil as base fluid. It was observed that, in water, nanoparticles efficiently worked rather than kerosene oil. Saqib et al. [33] studied the blood as a Brinkman type with composite magnetic particles in the existence of a perpendicularly applied magnetic field. Kumar et al. [34] reported the impact of radiation on the natural convection flow of Brinkman-type nanofluid on a vertical plate under the application of a magnetic field.

The subject of fractional calculus was introduced in 1965. It studies the derivative and integral with the order that is fractional [35]. Fractional calculus contains derivatives and integrals that are not local, making it much attractive for researchers. Fractional calculus briefly describes the memory effects [36, 37]. This memory helps to observe the past process. These properties make fractional calculus dominant over classical calculus. The research on fractional-order PDEs has shown that the results are comparatively more accurate and general than integer order [33]. Fractionalorder derivative and integral has vast applications in science and technology and is a highly emerging area in calculus, having application in biochemistry and fluid mechanics [38-41]. Fractional calculus is used in bioengineering, mathematics, finance, and disease dynamics [42, 43]. Imtiaz et al. [44] proposed a fractional model for blood flow containing metallic particles in a cylindrical tube. Singha and Sengupta [40] used fractional derivative to observe fluid flow with dusty particles. The effect of MHD on blood flow passing through human artery is observed by Sud and Sekhon [45]. Ahmad et al. [46] examined Jeffery fluid flow over exponentially of an infinite length using Caputo timefractional derivative and Caputo-Fabrizio fractional model. In this study, dual behavior for velocity is observed by the change in the memory parameter. A time-fractional model that deals with cancer therapy is developed by Asjad [47]. Butt et al. [48] used the fractional derivative to model MHD Jeffery fluid over a vertical plane with heat and mass transfer. It was found that temperature, velocity, and concentration can be enhanced by decreasing the value of the fraction parameter.

In the view of all the literature mentioned above, no one has considered the role of natural convection and heat transfer in blood flow. The present study reports the exact solutions of the unsteady free convection blood flow as a Brinkman-type fluid using the transverse magnetic field. Furthermore, the magnetic particles with different velocities are evenly distributed in the blood, passing through a heated cylindrical tube. The fluid contains blood as a liquid phase and particles in a solid phase. Flow is considered a two-phase flow like a liquid, and solid phases are flowing with different velocities. The classical fractional derivative is replaced by Caputo time-fractional derivative to obtain the fractional model. The Laplace and Finite Hankel transformations are used to getting velocities and temperature distributions for blood flow and suspended particles.

\section{Problem Formulation}

Consider the blood flow as a Brinkman-type fluid in a horizontal heated cylinder with radius $r$, as shown in Figure 1 . The motion of the fluid is taken in the $z$-direction. It is also considered that blood contains evenly distributed magnetic particles. Flow is taken as a two-phase flow. Therefore, momentum equations for particles and blood are defined separately. The transverse magnetic field is applied along with heat transfer through natural convection. Smooth flow of fluid is considered, which implies that the Reynolds number is very low, and the induced magnetic field can be neglected [44]. At time $t=0$, fluid and cylinder both are at rest with ambient temperature $T_{\infty}$. At the time, $t=0^{+}$, the fluid starts motion with velocity $U_{0}$, and temperature varies from $T_{\infty}$ to $T_{w}$.

The developed model contains momentum equation for fluid flow, obtained by Navier-Stokes equations, Maxwell's set of relations for the magnetic field, and Newton's second law for the particle velocity.

Maxwell set of equations are defined as $[49,50]$

$$
\left.\begin{array}{r}
\vec{\nabla} \times \vec{E}=-\frac{\partial \vec{B}_{1}}{\partial t} \\
\operatorname{div} \vec{B}_{1}=0 \\
\vec{\nabla} \times \vec{B}_{1}=\mu_{0} \vec{J}
\end{array}\right\}
$$

According to Ohm's law [51, 52],

$$
\vec{J}=\sigma_{0}(\vec{E}+\vec{V} \times \vec{B})
$$

where $\sigma_{0}$ is electrical conductivity and $\vec{V}$ is the velocity field. The electromagnetic force is defined as

$$
\vec{J} \times \vec{B}=-\sigma B_{0}^{2} U
$$

The momentum equation for blood flow is defined as $[33,53]$ 


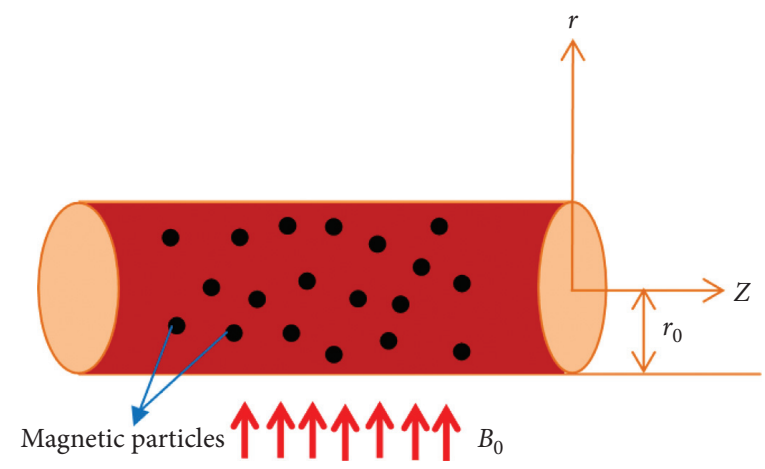

Figure 1: The geometry of the problem.

$$
\left.\begin{array}{c}
\frac{\partial u(r, t)}{\partial t}+\beta u(r, t)=-\frac{1}{\rho} \frac{\partial p}{\partial z}+\nu\left(\frac{\partial^{2} u(r, t)}{\partial r^{2}}+\frac{1}{r} \frac{\partial u(r, t)}{\partial r}\right) \\
+\frac{K N}{\rho}\left(u_{p}(r, t)-u(r, t)\right)+g \beta_{T}\left(T-T_{\infty}\right)-\frac{1}{\rho} \sigma B_{0}^{2} u(r, t)
\end{array}\right\} .
$$

The oscillating pressure gradient [54] is defined as

$$
-\frac{\partial p}{\partial z}=\lambda_{0}+\lambda_{1} \operatorname{Cos}(\omega t)
$$

Incorporating equation (5) in (4), (6) becomes

$$
\begin{aligned}
\frac{\partial u(r, t)}{\partial t}+\beta u(r, t)= & \frac{1}{\rho}\left(\lambda_{0}+\lambda_{1} \operatorname{Cos}(\omega t)\right)+v\left(\frac{\partial^{2} u(r, t)}{\partial r^{2}}+\frac{1}{r} \frac{\partial u(r, t)}{\partial r}\right) \\
& +\frac{K N}{\rho}\left(u_{p}(r, t)-u(r, t)\right)+g \beta_{T}\left(T-T_{\infty}\right)-\frac{1}{\rho} \sigma B_{0}^{2} u(r, t),
\end{aligned}
$$

where $(K N / \rho)\left(u_{p}(r, t)-u(r, t)\right)$ indicates the force between particles and fluid.

The momentum equation for magnetic particles is defined as [55]

$$
m \frac{\partial u_{p}(r, t)}{\partial t}=K\left(u(r, t)-u_{p}(r, t)\right) .
$$

The equation for energy is as follows

$$
\rho C p \frac{\partial T}{\partial t}=k\left(\frac{\partial^{2} T}{\partial r^{2}}+\frac{1}{r} \frac{\partial T}{\partial r}\right), \quad t>0, r \in\left(0, r_{0}\right),
$$

subjected to the following initial and boundary conditions:

$$
\left.\begin{array}{r}
u(r, 0)=0, u_{p}(r, 0)=0, T(r, 0)=T_{\infty}, \\
u\left(r_{0}, t\right)=H(t) U_{0}, u_{p}\left(r_{0}, t\right)=H(t) U_{0}\left[1-e^{-(K / m) t}\right], T\left(r_{0}, t\right)=T_{w}, \\
\left.\frac{\partial u}{\partial r}\right|_{r=0}=0
\end{array}\right\},
$$

using the following dimensionless variables,

$$
\begin{aligned}
f & =\frac{u}{u_{0}}, \\
g & =\frac{u_{p}}{u_{0}}, \\
\tau & =\frac{t \nu}{r_{0}^{2}}, \\
r_{1} & =\frac{r}{r_{0}}, \\
A_{0} & =\frac{\lambda_{0} r_{0}^{2}}{\mu u_{0}}, \\
A_{1} & =\frac{\lambda_{1} r_{0}^{2}}{\mu u_{0}}, \\
\theta & =\frac{T-T_{\infty}}{T_{w}-T_{\infty}} .
\end{aligned}
$$

The dimensionless form of the system with initial and boundary conditions are 


$$
\begin{aligned}
& \frac{\partial f\left(r_{1}, \tau\right)}{\partial \tau}=A_{0}+A_{1} \operatorname{Cos}(\omega t)+\frac{\partial^{2} f\left(r_{1}, \tau\right)}{\partial r_{1}^{2}}+\frac{1}{r_{1}} \frac{\partial f\left(r_{1}, \tau\right)}{\partial r_{1}}+P_{c}\left(g\left(r_{1}, \tau\right)-f\left(r_{1}, \tau\right)\right)-M_{0} f\left(r_{1}, \tau\right)+\operatorname{Gr} \theta\left(r_{1}, \tau\right), \\
& \frac{\partial g\left(r_{1}, \tau\right)}{\partial \tau}=P_{m}\left(f\left(r_{1}, \tau\right)-g\left(r_{1}, \tau\right)\right), \\
& \frac{\partial \theta\left(r_{1}, \tau\right)}{\partial \tau}=\frac{1}{\operatorname{Pr}}\left(\frac{\partial^{2} \theta\left(r_{1}, \tau\right)}{\partial r_{1}^{2}}+\frac{1}{r_{1}} \frac{\partial \theta\left(r_{1}, \tau\right)}{\partial r_{1}}\right), \quad \tau>0, r_{1} \in(0,1), \\
& \left.f\left(r_{1}, 0\right)=0, g\left(r_{1}, 0\right)=0, \theta\left(r_{1}, 0\right)=0, f(1, \tau)=1, g(1, \tau)=\left[1-e^{-b t}\right], \theta(1, t)=1,\left.\frac{\partial f\left(r_{1}, \tau\right)}{\partial r_{1}}\right|_{r_{1}=0}=0\right\}, \\
& D_{t}^{\alpha} f(r, \tau)=\frac{1}{\Gamma(1-\alpha)} \int_{0}^{t} \frac{f^{\prime}(\tau)}{(t-\tau)^{\alpha}} \mathrm{d}(\tau), \quad 0<\alpha<1,
\end{aligned}
$$

where

$$
\begin{aligned}
P_{c} & =\frac{K N r_{0}^{2}}{\mu}, \\
M & =\frac{\sigma B_{0} r_{0}^{2}}{\mu}, \\
\beta_{1} & =\frac{\beta r_{0}^{2}}{\nu}, \\
P_{m} & =\frac{\nu K}{r_{0}^{2}}, \\
M_{0} & =M-\beta_{1}, \\
\mathrm{Gr} & =\frac{g r_{0}^{2} \beta_{T}\left(T_{w}-T_{\infty}\right)}{u_{0} \nu}, \\
\operatorname{Pr} & =\frac{\mu C_{p}}{k}, \\
b & =\frac{K r_{0}^{2}}{m \nu},
\end{aligned}
$$

where $P_{c}$ is the dimensionless particle concentration parameter.

Now, applying Caputo time derivative to equations (11)-(13), we obtain

$$
\begin{aligned}
D_{t}^{\alpha} f\left(r_{1}, \tau\right)= & A_{0}+A_{1} \operatorname{Cos}(\omega t)+\frac{\partial^{2} f\left(r_{1}, \tau\right)}{\partial r_{1}^{2}}+\frac{1}{r_{1}} \frac{\partial f\left(r_{1}, \tau\right)}{\partial r_{1}} \\
& +P_{c}\left(g\left(r_{1}, \tau\right)-f\left(r_{1}, \tau\right)\right)-M_{0} f\left(r_{1}, \tau\right)+\operatorname{Gr} \theta\left(r_{1}, \tau\right), \\
D_{t}^{\alpha} g\left(r_{1}, \tau\right)= & P_{m}\left(f\left(r_{1}, \tau\right)-g\left(r_{1}, \tau\right)\right) \\
D_{t}^{\alpha} \theta\left(r_{1}, \tau\right)= & \frac{1}{\operatorname{Pr}}\left(\frac{\partial^{2} \theta\left(r_{1}, \tau\right)}{\partial r_{1}^{2}}+\frac{1}{r_{1}} \frac{\partial \theta\left(r_{1}, \tau\right)}{\partial r_{1}}\right)
\end{aligned}
$$

where

which is defined as Caputo time-fractional derivative [56].

\section{The Solution of the Problem}

The Laplace and Henkel transform is employed to get the required solution for the blood and particle velocities. Both transforms are defined as [33]

$$
\left.\begin{array}{r}
L\{f(r, t)\}(q)=\bar{f}(q)=\int_{0}^{\infty} f(r, t) e^{-q t} \mathrm{~d} t, \\
H\{\bar{f}(r, q)\}\left(r_{n}\right)=\bar{f}_{H}\left(r_{n}, q\right)=\int_{0}^{1} r \bar{f}(r, t) J_{0}\left(r r_{n}\right) \mathrm{d} r
\end{array}\right\},
$$

where $J_{0}\left(r_{n}\right)$ is Bessel's function of the first kind of order zero and $r_{n}$ are positive roots of the equation $J_{0}(x)=0$.

3.1. Temperature Field Calculation. Applying Laplace transform to equations (14) and (18), obtained equations are

$$
q^{\alpha} \bar{\theta}\left(r_{1}, q\right)=\frac{1}{\operatorname{Pr}}\left(\frac{\mathrm{d}^{2} \bar{\theta}\left(r_{1}, q\right)}{\mathrm{d} r_{1}^{2}}+\frac{1}{r_{1}} \frac{\mathrm{d} \bar{\theta}\left(r_{1}, q\right)}{\mathrm{d} r_{1}}\right),
$$

$$
\bar{\theta}(1, q)=\frac{1}{q},
$$

where $\bar{\theta}\left(r_{1}, q\right)$ is Laplace transform of $\theta\left(r_{1}, t\right)$, where $q$ denotes transformation variable.

By the using Finite Hankel transform to equation (21) and putting values from equation (22), we obtain

$$
\bar{\theta}_{H}\left(r_{1 n}, q\right)=\frac{r_{1 n} J\left(r_{1 n}\right)}{\operatorname{Pr}} \frac{1}{q\left(q^{\alpha}+a_{1}\right)},
$$

where $\left(r_{1 n}^{2} / \mathrm{Pr}\right)=a_{1}$.

$\bar{\theta}_{H}\left(r_{1 n}, q\right)$ shows Hankel transform of $\bar{\theta}(r, q)$. Equation (23) reduces to

$$
\bar{\theta}_{H}\left(r_{1 n}, q\right)=\frac{J_{1}\left(r_{1 n}\right)}{r_{1 n}} \frac{1}{q}-\frac{J_{1}\left(r_{1 n}\right)}{r_{1 n}} \frac{q^{-(1-\alpha)}}{q^{\alpha}+a 1} .
$$


Applying inverse Laplace transform by using Lorenzo and Hartley's $R_{\beta_{0}, v}(-\lambda, \tau)$ functions [57] to equation (24),

$$
\begin{array}{r}
\theta_{H}\left(r_{1 n}, \tau\right)=\frac{J_{1}\left(r_{1 n}\right)}{r_{1 n}}-\frac{J_{1}\left(r_{1 n}\right)}{r_{1 n}} R(\alpha, 1-\alpha)\left(\tau,-a_{1}\right), \\
L^{-1}\left(\frac{s^{-v}}{s^{\beta_{0}}+\lambda}\right)=R_{\beta_{0}, v}(-\lambda, \tau)=\sum_{n=0}^{\infty} \frac{(-\lambda)^{n} \tau^{(n+1) \beta_{0}-1-v}}{\Gamma\left\{(n+1) \beta_{0}-v\right\}} .
\end{array}
$$

Applying the inverse Henkel transform to equation (25), we obtain

$$
\theta\left(r_{1}, \tau\right)=1-2 \sum_{n=1}^{\infty} \frac{J_{0}\left(r_{1} r_{1 n}\right)}{r_{1 n} J_{1}\left(r_{1 n}\right)} R(\alpha, 1-\alpha)\left(-a_{1}, \tau\right) .
$$

3.2. The Calculation for Blood Flow. Applying Laplace transform to equations (16) and (17) and using equation (13), we obtain

$$
\begin{aligned}
q^{\alpha} \bar{f}\left(r_{1}, q\right)= & \left(\frac{A_{0}}{q}+\frac{A_{1} q}{q^{2}+\omega^{2}}\right)+\left(\frac{\partial^{2} \bar{f}\left(r_{1}, q\right)}{\partial r_{1}^{2}}+\frac{1}{r_{1}} \frac{\partial \bar{f}\left(r_{1}, q\right)}{\partial r_{1}}\right) \\
& +P_{c}\left(\bar{g}\left(r_{1}, q\right)-\bar{f}\left(r_{1}, q\right)\right)-M_{0} \bar{f}\left(r_{1}, q\right) \\
& +\operatorname{Gr} \bar{\theta}\left(r_{1}, q\right),
\end{aligned}
$$

$$
\bar{g}\left(r_{1}, q\right)=\frac{\bar{f}\left(r_{1}, q\right)}{P_{m} q^{\alpha}+1} .
$$

Applying the Hankel transform to equations (27) and (28) using equation (22), we obtain

$$
\begin{aligned}
q^{\alpha} \bar{f}_{H}\left(r_{1 n}, q\right)= & \left(\frac{A_{0}}{q}+\frac{A_{1} q}{q^{2}+\omega^{2}}\right) \frac{J_{1}\left(r_{1 n}\right)}{r 1 n}+\left(-r_{1 n}^{2} \bar{f}_{H}\left(r_{1 n}, q\right)+r_{1 n} J_{1}\left(r_{1 n}\right) \bar{f}(1, q)\right) \\
& +P_{c}\left(\bar{g}_{H}\left(r_{1 n}, q\right)-\bar{f}_{H}\left(r_{1 n}, q\right)\right)-M_{0} \bar{f}_{H}\left(r_{1 n}, q\right)+G r \bar{\theta}_{H}\left(r_{1 n}, q\right), \\
\bar{g}_{H}\left(r_{1 n}, q\right)= & \frac{1}{P_{m}}\left(\frac{1}{q^{\alpha}+\left(1 / P_{m}\right)}\right) \bar{f}_{H}\left(r_{1 n}, q\right),
\end{aligned}
$$

where

$$
\begin{aligned}
\int_{0}^{1}\left(\frac{\partial^{2} \bar{f}\left(r_{1}, q\right)}{\partial r_{1}^{2}}+\frac{1}{r_{1}} \frac{\partial \bar{f}\left(r_{1}, q\right)}{\partial r_{1}}\right) \mathrm{d} r_{1}= & -r_{1 n}^{2} \cdot \bar{f}_{H}\left(r_{1 n}, q\right) \\
& +r_{1 n} J_{1}\left(r_{1 n}\right) \bar{f}(1, q) .
\end{aligned}
$$$$
\bar{F}_{0 n}(q)=\left(\frac{A_{0}}{q}+\frac{A_{1} q}{q^{2}+\omega^{2}}\right) \frac{J_{1}\left(r_{1 n}\right)}{r_{1 n}}
$$$$
k_{1}=\frac{r_{1 n}^{2}+M_{0}}{P_{m}}
$$$$
k_{0}=\frac{P_{m} r_{1 n}^{2}+\left(1+P_{m}\left(P_{c}+M_{0}\right)\right)}{P_{m}},
$$
to

Simplifying equation (29) and using equation (22) leads

$$
\left(\frac{q^{2 \alpha}+k_{0} q^{\alpha}+k_{1}}{q^{\alpha}+k_{2}}\right) \bar{f}_{H}\left(r_{1 n}, q\right)=\bar{F}_{0 n}(q)+\frac{J_{1}\left(r_{1 n}\right)}{q}+\operatorname{Gr} \bar{\theta}\left(r_{1 n}, q\right),
$$

$$
k_{2}=\frac{1}{P_{m}}
$$

Substituting equations (25) into (32), then, after simplification, it takes the form

where

$$
\bar{f}_{H}\left(r_{1 n}, q\right)=\left\{\frac{r_{1 n} J_{1}\left(r_{1 n}\right)}{q}+\bar{F}_{0 n}(q) \frac{J_{1}\left(r_{1 n}\right)}{r_{1 n}}+\operatorname{Gr}\left(\left(\frac{1}{q}-\frac{q^{\alpha-1}}{q^{\alpha}+a_{1}}\right) \frac{J_{1}\left(r_{1 n}\right)}{r_{1 n}}\right)\right\}\left(\frac{q^{\alpha}+k_{2}}{\left(q^{\alpha}+k_{3}\right)\left(q^{\alpha}+k_{4}\right)}\right) .
$$


Equation (34) can be written as

$$
\begin{aligned}
\bar{f}_{H}\left(r_{1 n}, q\right)= & \frac{J_{1}\left(r_{1 n}\right)}{r_{1 n}} \frac{1}{q}-\left[\left\{\frac{1}{q}+H 0\left(\frac{q^{-1}}{\left(q^{\alpha}+k 3\right)}\right)+H 1\left(\frac{q^{-1}}{\left(q^{\alpha}+k 4\right)}\right)\right\}\right. \\
& -\left\{H_{2} A_{0}\left(\frac{q^{-1}}{\left(q^{\alpha}+k_{3}\right)}\right)+H_{3} A_{0}\left(\frac{q^{-1}}{\left(q^{\alpha}+k_{4}\right)}\right)+H_{2} A_{1}\left(\frac{1}{\left(q^{\alpha}+k_{3}\right)} \frac{q}{\left(q^{2}+\omega^{2}\right)}\right)+H_{3} A_{1}\left(\frac{1}{\left(q^{\alpha}+k_{4}\right)} \frac{q}{\left(q^{2}+\omega^{2}\right)}\right)\right\} \\
& \left.-\operatorname{Gr}\left\{H_{9}\left(\frac{q^{-1}}{\left(q^{\alpha}+k_{3}\right)}\right)+H_{10}\left(\frac{q^{-1}}{\left(q^{\alpha}+k_{4}\right)}\right)-H_{8}\left(\frac{q^{-1}}{\left(q^{\alpha}+a_{1}\right)}\right)\right\}\right] \frac{J_{1}\left(r_{1 n}\right)}{r_{1 n}}
\end{aligned}
$$

where

$$
\begin{aligned}
k_{3} & =\frac{k_{0}+\sqrt{k_{0}-4 k_{1}}}{2}, \\
k_{4} & =\frac{k_{0}-\sqrt{k_{0}-4 k_{1}}}{2}, \\
k_{5} & =k_{3}+k_{4}, \\
k_{6} & =k_{3} k_{4}, \\
k_{7} & =r_{1 n}^{2}-k_{5}, \\
k_{8} & =r_{1 n}^{2} k_{2}-k_{6}, \\
H_{0} & =\frac{k_{8}-k_{7} k_{3}-k_{3}^{2}}{k_{3}-k_{4}}, \\
H_{1} & =\frac{-k_{8}+k_{7} k_{4}+k_{4}^{2}}{\left(k_{3}-k_{4}\right)} \\
H_{2} & =\frac{k_{1}-k_{2}}{k_{3}-k_{4}}, \\
H_{3} & =\frac{k_{2}-k_{4}}{k_{3}-k_{4}}, \\
H_{4} & =\frac{a_{1}}{a_{1}-k_{3}}, \\
H_{5} & =\frac{k_{3}}{a_{1}-k_{3}}, \\
H_{6} & =\frac{a_{1}}{a_{1}-k_{4}}, \\
H_{9} & =H_{4}-k_{4}+H_{5}, \\
H_{10} & =H_{3}+H_{7} . \\
H_{1} & \\
H_{1} & \\
H_{1} &
\end{aligned}
$$

Taking the Laplace inverse of equation (35), we obtain

$$
\begin{aligned}
f_{H}\left(r_{1 n}, \tau\right)= & \frac{J_{1}\left(r_{1 n}\right)}{r_{1 n}}-\frac{J_{1}\left(r_{1 n}\right)}{r_{1 n}} \\
& \cdot\left\{\begin{array}{c}
1+N_{1} R_{\alpha,-1}\left(-k_{3}, \tau\right)+N_{2} R_{\alpha,-1}\left(-k_{4}, \tau\right) \\
+N_{3} \cos (\omega t) * F_{\alpha}\left(-k_{3}, \tau\right) \\
+N_{4} \cos (\omega t) * F_{\alpha}\left(-k_{4}, \tau\right) \\
+N_{5} R_{\alpha,-1}\left(-a_{1}, \tau\right)
\end{array}\right\},
\end{aligned}
$$

where Robotnov Hartley's function [58] is defined as

$$
\begin{aligned}
L^{-1}\left(\frac{1}{s^{\beta_{0}}+\lambda}\right) & =F_{\beta_{0}}(-\lambda, \tau)=\sum_{n=0}^{\infty} \frac{(-\lambda)^{n} \tau^{(n+1) \beta_{0}-1}}{\Gamma\left\{(n+1) \beta_{0}\right\}}, \\
N_{1} & =H_{0}-H_{2} A_{0}-\mathrm{Gr} H_{9}, \\
N_{2} & =H_{1}-H_{3} A_{0}-\mathrm{Gr} H_{10} \\
N_{3} & =-H_{2} A_{1} \\
N_{4} & =-H_{3} A_{1}, \\
N_{5} & =\mathrm{GrH}_{8} .
\end{aligned}
$$

Applying inverse Hankel transform to equation (37) leads to

$$
f\left(r_{1}, \tau\right)=1-2 \sum_{n=1}^{\infty} \frac{J_{0}\left(r_{1} r_{1 n}\right)}{r_{1 n} J_{1}\left(r_{1 n}\right)}\left\{\begin{array}{c}
1+N_{1} R_{\alpha,-1}\left(-k_{3}, \tau\right)+N_{2} R_{\alpha,-1}\left(-k_{4}, \tau\right) \\
+N_{3} \cos (\omega t) * F_{\alpha}\left(-k_{3}, \tau\right) \\
+N_{4} \cos (\omega t) * F_{\alpha}\left(-k_{4}, \tau\right) \\
+N_{5} R_{\alpha,-1}\left(-a_{1}, \tau\right)
\end{array}\right\}
$$


Taking inverse Laplace transform of equation (30) and by using Lorenzo-Hartley function,

$$
g_{H}\left(r_{1 n}, \tau\right)=\frac{1}{P_{m}} F_{\alpha}\left(-\frac{1}{P_{m}}, \tau\right) * f_{H}\left(r_{1 n}, \tau\right) .
$$

Taking inverse Finite Hankel transform of equation (40) reduces to

$$
g\left(r_{1}, \tau\right)=\frac{1}{P_{m}} F_{\alpha}\left(-\frac{1}{P_{m}}, \tau\right) * f\left(r_{1}, \tau\right),
$$

\subsection{Limiting Cases. Case 1: take $\alpha=1$.}

When $\alpha \longrightarrow 1$ the Lorenzo and Hartley's and Robotnov and Hartley's function reduces to [58]

$$
\begin{aligned}
R_{1,-1}(-\lambda, \tau) & =L^{-1}\left(\frac{s^{-1}}{s+\lambda}\right)=\sum_{n=0}^{\infty} \frac{(-\lambda)^{n} \tau^{n+1}}{k !}=\frac{1-e^{\lambda \tau}}{\lambda}, \\
R_{(1,0)} & =e^{-\lambda \tau} \\
L^{-1}\left(\frac{1}{s+\lambda}\right) & =e^{-\lambda \tau}=F_{1}(-\lambda, \tau)=\sum_{n=0}^{\infty} \frac{(-\lambda)^{n} \tau^{n}}{k !} .
\end{aligned}
$$

Equations (26), (39), and (41) reduce to

$$
\begin{aligned}
\theta\left(r_{1}, \tau\right)= & 1-2 \sum_{n=1}^{\infty} \frac{J_{0}\left(r_{1} r_{1 n}\right)}{r_{1 n} J_{1}\left(r_{1 n}\right)} e^{(-\alpha 1 \tau)}, \\
f\left(r_{1}, \tau\right)= & 1-2 \sum_{n=1}^{\infty} \frac{J 0\left(r_{1} r_{1 n}\right)}{r_{1 n} J_{1}\left(r_{1 n}\right)}\left\{1+N_{01}\left(1-e^{k 3 \tau}\right)+N_{02}\left(1-e^{k 4 \tau}\right)+N_{03}\left(e^{-k 3 \tau}+\cos (\omega t)+w_{0} \sin (\omega t)\right)\right. \\
& \left.+N_{04}\left(e^{-k 4 \tau}+\cos (\omega t)+w_{1} \sin (\omega)\right)+N_{05}\left(1-e^{a 1 \tau}\right)\right\}, \\
g\left(r_{1}, \tau\right)= & \frac{1}{P_{m}} e^{-\left(1 / P_{m}\right) \tau} * f\left(r_{1}, \tau\right) .
\end{aligned}
$$

Case 2: when $\beta \longrightarrow 0$ in present general solutions, the problem reduces to the result obtained by Ali et al. [59], when $(1 / \beta) \longrightarrow 0$ :

$$
\begin{aligned}
N_{01} & =\frac{N_{1}}{k_{3}}, \\
N_{02} & =\frac{N_{2}}{k_{4}}, \\
N_{03} & =\frac{N_{3}}{k_{3}}\left(\frac{k_{3}^{2}}{k_{3}^{2}-w^{2}}\right), \\
w_{0} & =\frac{w}{k_{3}^{2}}, \\
N_{04} & =\frac{N_{4}}{k_{4}}\left(\frac{k_{4}^{2}}{k_{4}^{2}-w^{2}}\right), \\
w_{1} & =\frac{w}{k_{4}^{2}}, \\
N_{05} & =\frac{N_{5}}{a_{1}} .
\end{aligned}
$$

\section{Graphical Results and Discussion}

This section briefly highlights the influence of different parameters $\alpha, \beta, M, P_{c}$, and $P_{m}$ on fluid temperature, velocities of blood, and magnetic particles by plotting various graphs.

Figures 2(a) and 2(b) show the impact of the fractional parameter $\alpha$ on temperature distribution. With the variation in $\alpha$, different graphs for temperature distribution are developed. These graphs are drawn for fractional parameters keeping all the other physical parameters and the time parameter constant. This variation is termed as a memory effect that cannot be considered in the integer ordered models. The obtained curves will help the experimentalist to best fit the curve with the curve drawn for the experimental data. The behavior of blood's velocity and magnetic particles has been observed in Figures 3 and 4 for different values of the fractional parameter. It is clear from these figures that the velocity shows opposite behavior for a long and a short time, which describes the effects of memory consideration by the fractional model as discussed in the description of Figures 2(a) and 2(b). These layers can help the researchers to investigate the fluid and the particles' behavior at any point. Hence, fractional derivatives provide the best way to describe the velocity of blood at a fixed time to validate the experimental or real-time flow behavior.

Figure 5 portrays the influence of the Brinkman-type fluid parameter on blood and particle velocities. From the figure, it is noticed that when the Brinkman-type fluid parameter is increased, the velocities of both the fluid and particles decreased. Since the Brinkman parameter is the ratio of drag force and density of fluid [30], the increase in the Brinkman-type fluid parameter increases in friction/drag forces and reduces the blood and particles' velocities. 


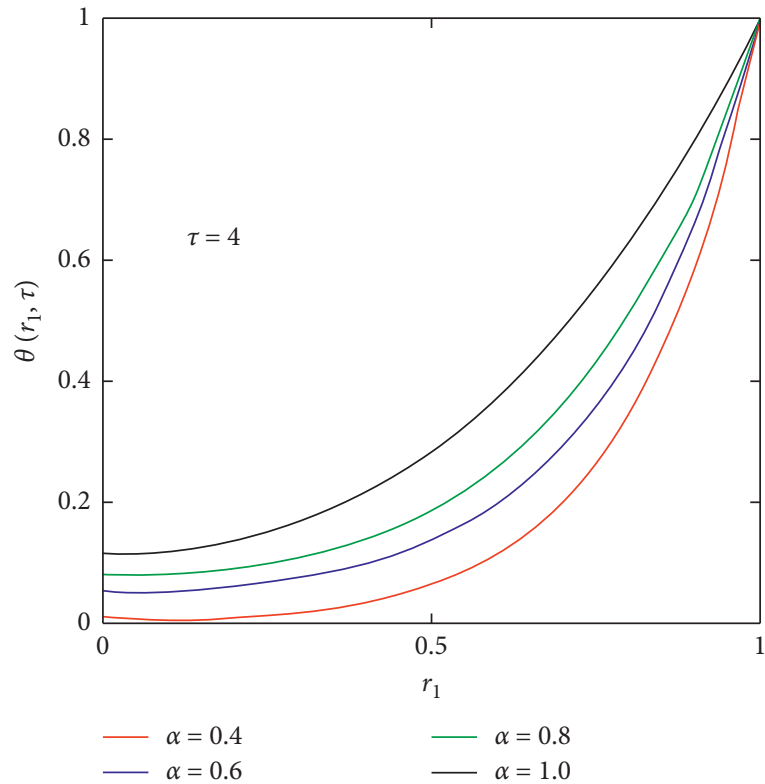

(a)

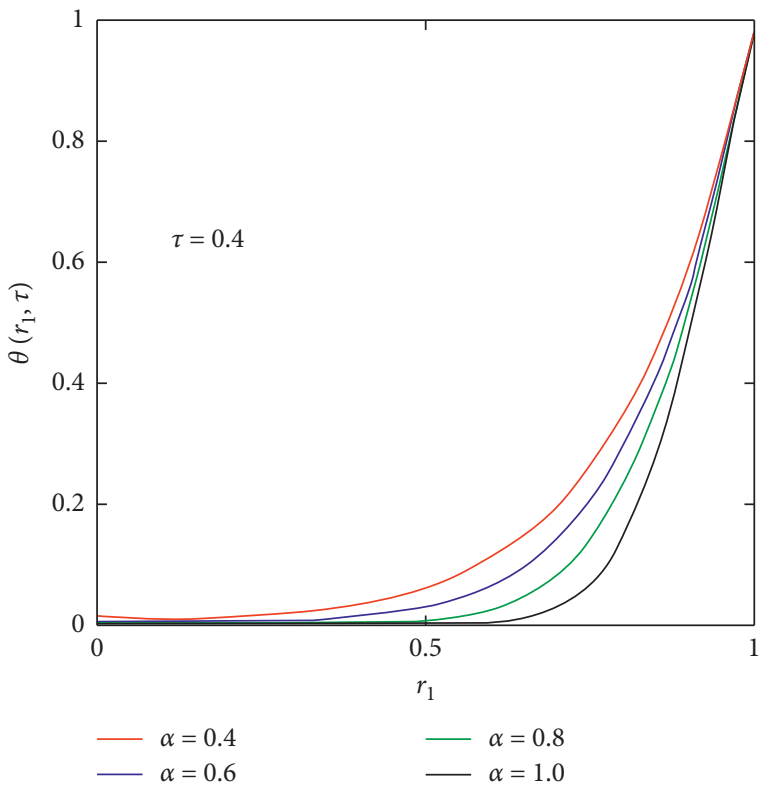

(b)

Figure 2: Temperature graph for different values of $\alpha$ for long and short time when $\operatorname{Pr}=22.64$.

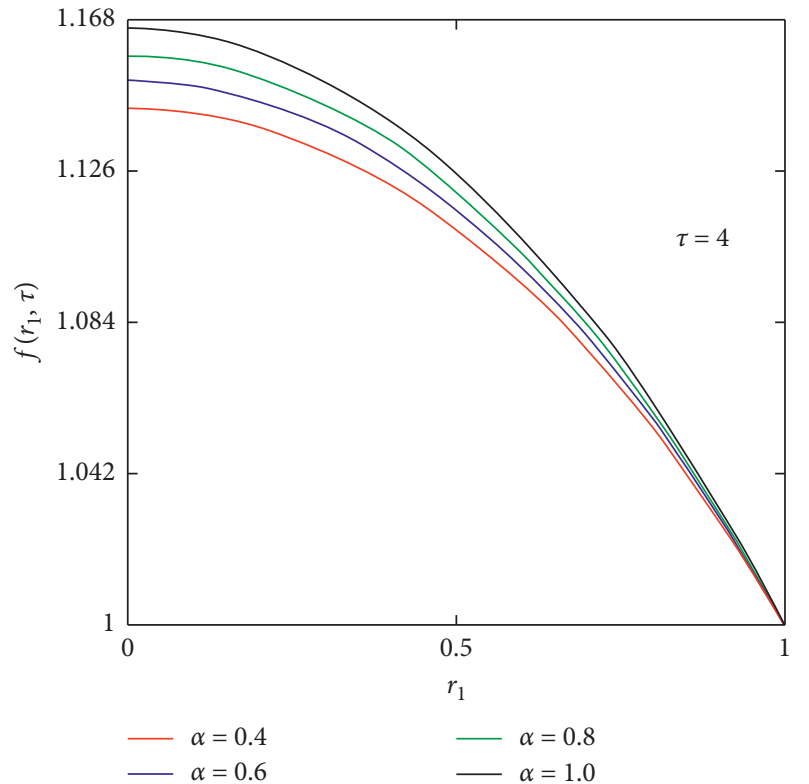

(a)

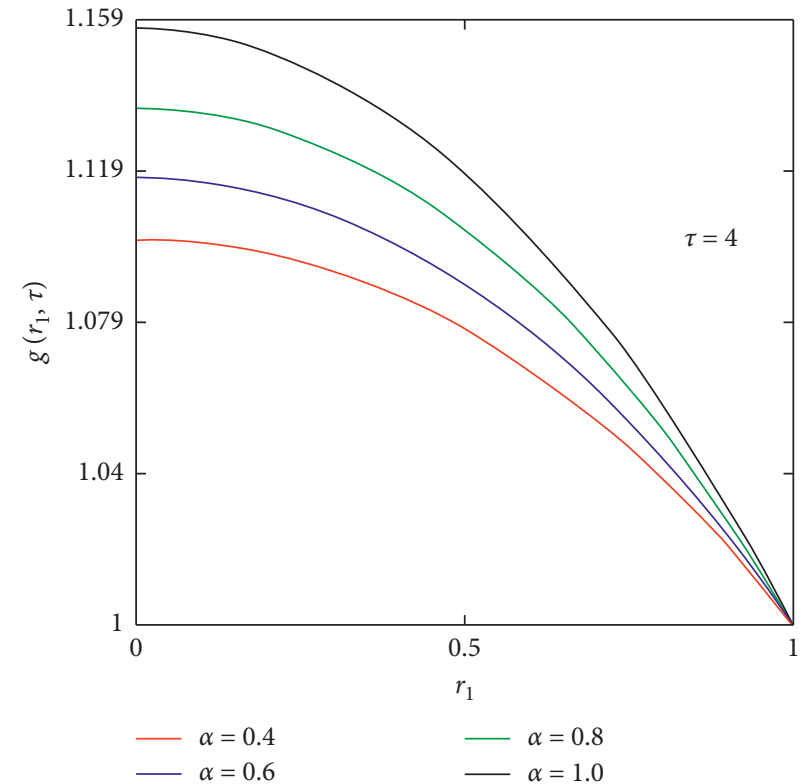

(b)

Figure 3: Variation in blood and magnetic particles profile against $r_{1}$ due to $\alpha$ for long time: $\beta=0.5, M=0.5, A_{0}=0.5, A_{1}=0.6, P_{m}=0.8, P_{c}=0.5, \omega t=(5 \pi / 8), \operatorname{Pr}=22.64$, and $\mathrm{Gr}=3.2 \times 10^{2}$.

Figure 6 displays the impact of the magnetic parameter on blood and particle velocity. When the magnetic parameter is increased, velocities of both the fluid and particle show decreasing behavior. This happens due to the Lorentz force, which is opposite to the flow direction. When the values of the magnetic parameter are increased, the Lorentz force increases, which slows down both the velocities. This result indicates that the magnetic field helps control the blood flow during treatment without affecting the healthy tissues. Figures 7 and 8 display the behavior of fluid and particle 


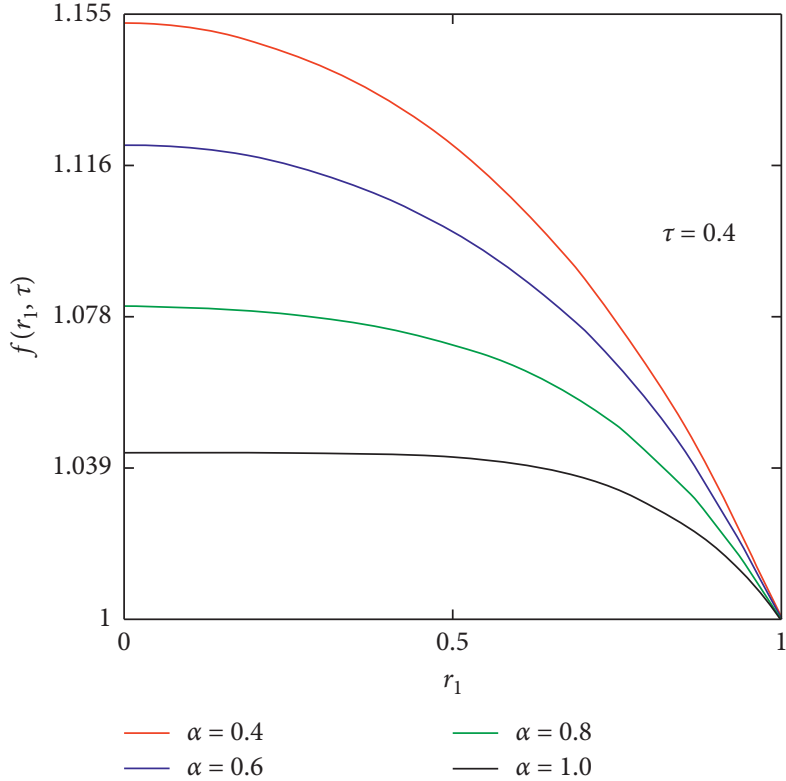

(a)

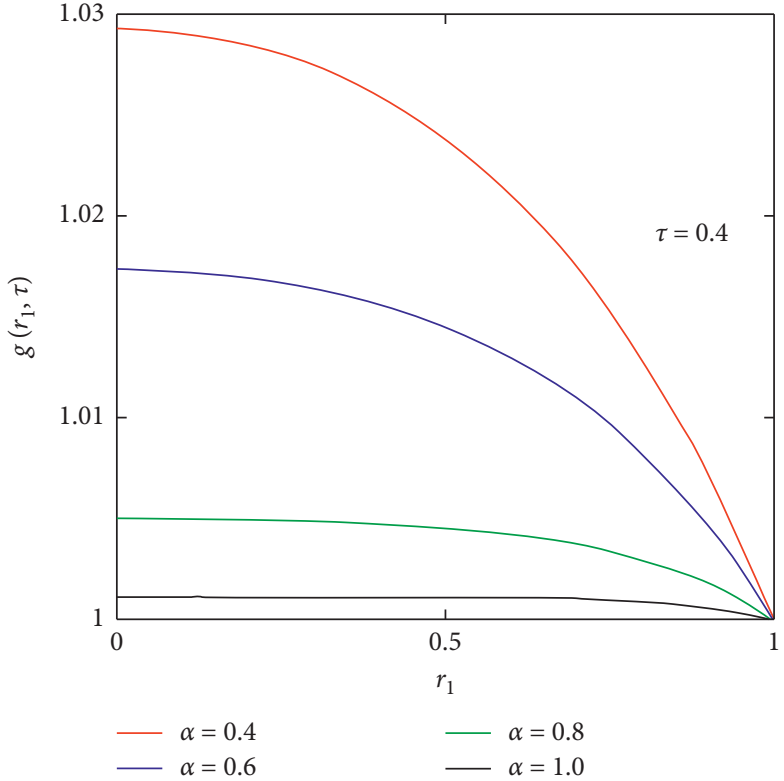

(b)

Figure 4: Variation in blood and magnetic particles profile against $r_{1}$ due to $\alpha$ for short time: $\tau<1 \beta=0.5, M=0.5, A_{0}=0.5, A_{1}=0.6, P_{m}=0.8, P_{c}=0.5, \omega t=(5 \pi / 8), \operatorname{Pr}=22.64$, and $\mathrm{Gr}=3.2 \times 10^{2}$.

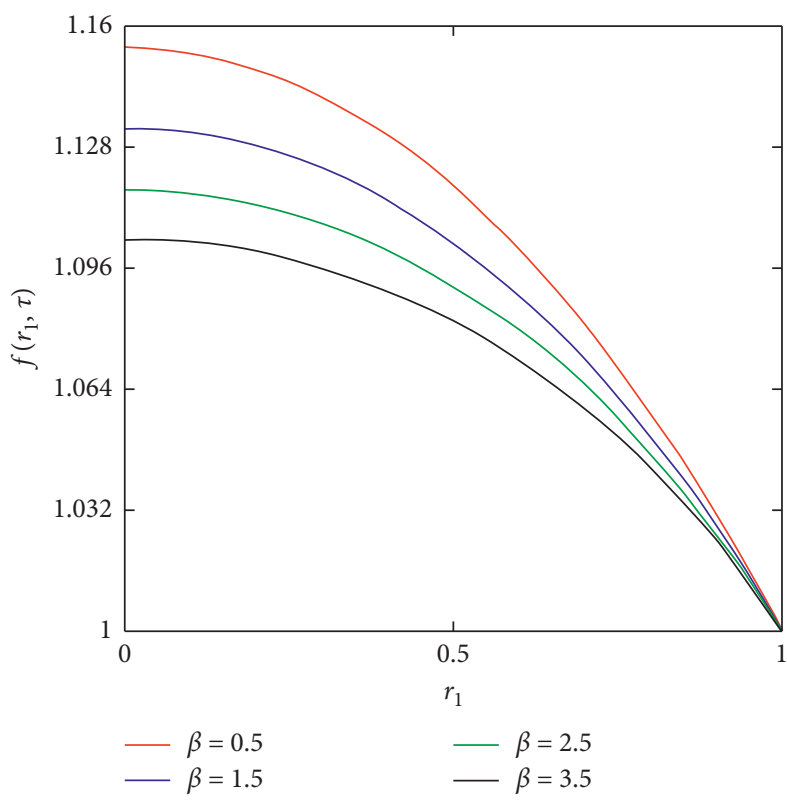

(a)

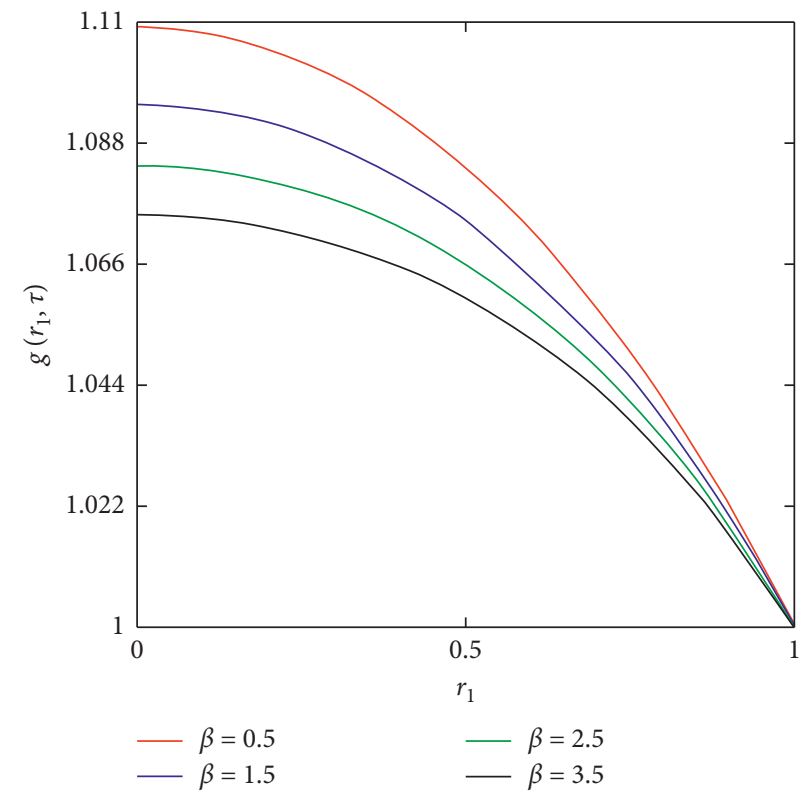

(b)

FIgURE 5: Variation in blood and magnetic particles profile against $r_{1}$ due to variation in the Brinkman parameter: $\alpha=0.5, M=0.5, A_{0}=0.5, A_{1}=0.6, P_{m}=0.8, P_{c}=0.5, \omega t=(5 \pi / 8), \operatorname{Pr}=22.64$, and $\mathrm{Gr}=3.2 \times 10^{2}$.

velocity for various values $P_{c}$ for a long and short time. Decreasing behavior is observed for a long and short time. The physics behind this is, due to an increase in particle concentration, the blood becomes denser and thicker, which slows down the motion of fluid and particles. Since the flow is fully developed, fluid gets its maximum velocity at the center, while near the wall, its velocity is relatively slow. The same behavior is observed by Saqib et al. [33]. Figure 9 depicts that rising values of magnetic particle mass parameter decreases the velocities of blood and particle. The 


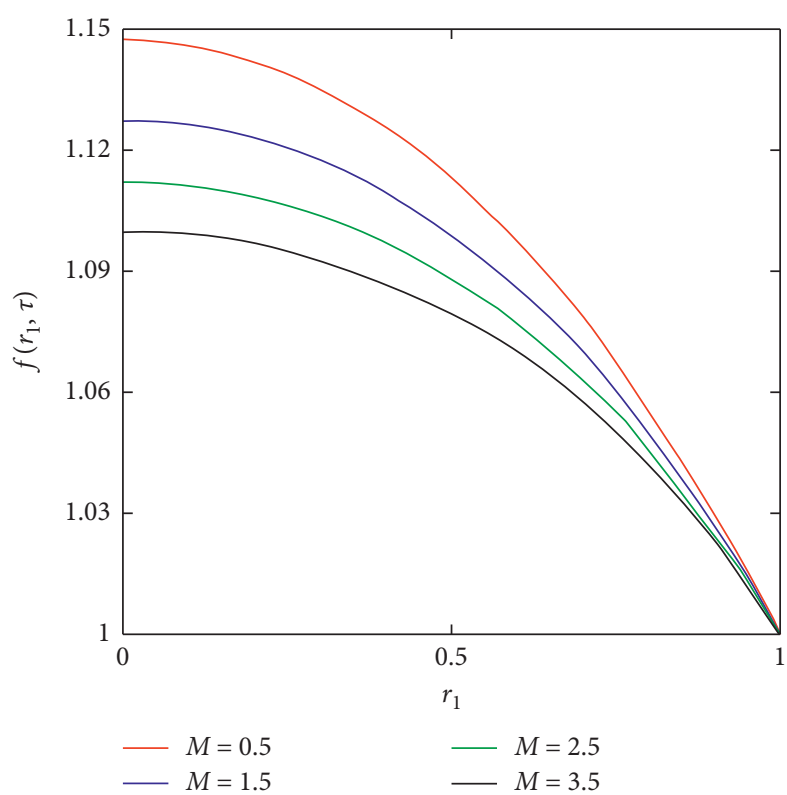

(a)

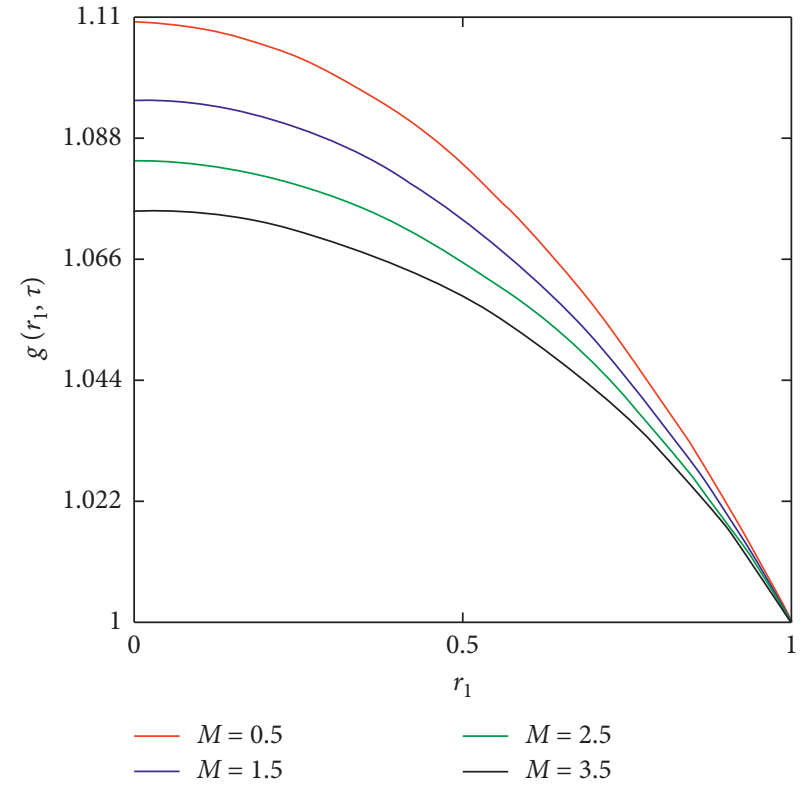

(b)

FIGURE 6: Variation in blood and magnetic particles profile against $r_{1}$ due to variation in the magnetic parameter: $\alpha=0.5, \beta=0.5, A_{0}=0.5, A_{1}=0.6, P_{m}=0.8, P_{c}=0.5, \omega t=(5 \pi / 8), \operatorname{Pr}=22.64$, and $\mathrm{Gr}=3.2 \times 10^{2}$.

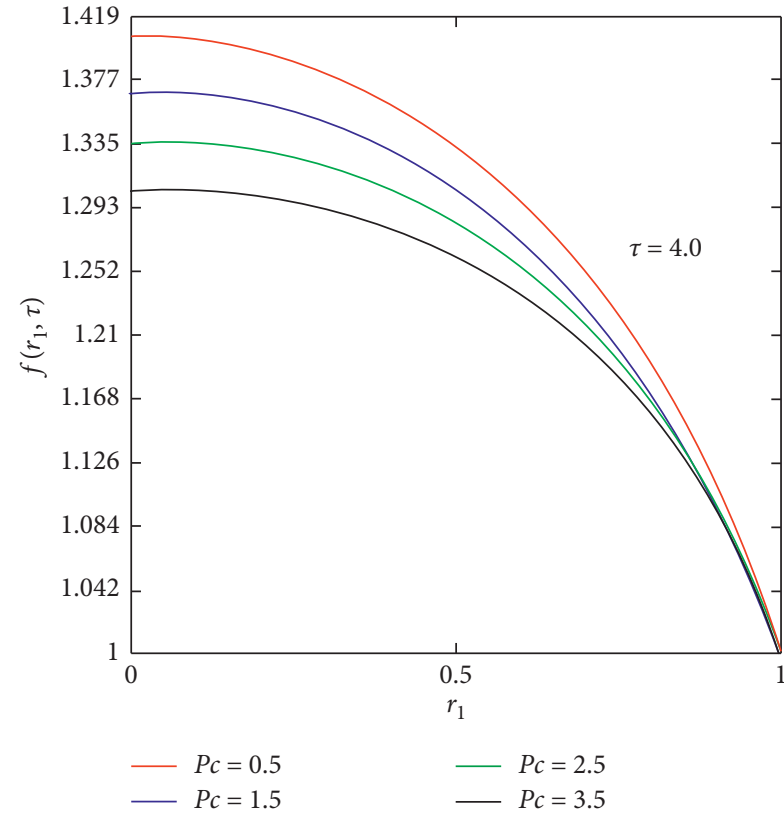

(a)

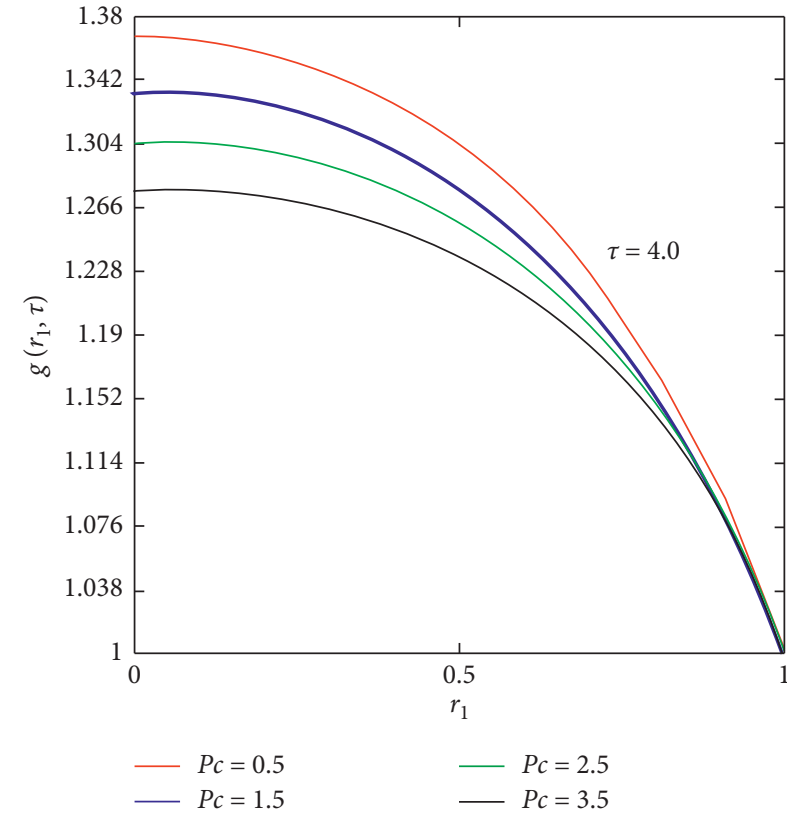

(b)

FIgURE 7: Variation in blood and magnetic particles profile against $r_{1}$ due to variation in $P_{c}$ for long time: $\alpha=0.5, \beta=0.5, A_{0}=0.5, A_{1}=0.6, P_{m}=0.8, \omega t=(5 \pi / 8), \operatorname{Pr}=22.64$, and $\mathrm{Gr}=3.2 \times 10^{2}$.

reason for such behavior is that large size magnetic particles make the blood more viscous and hence retards the flow. Nandkeolyar and Das [60] noticed the similar behavior for fluid velocity by variation in the particle mass parameter.
This shows that magnetic particles with small size are more effective for treatments as can easily move through blood and easily reach the target area, including liver and heart cells. 


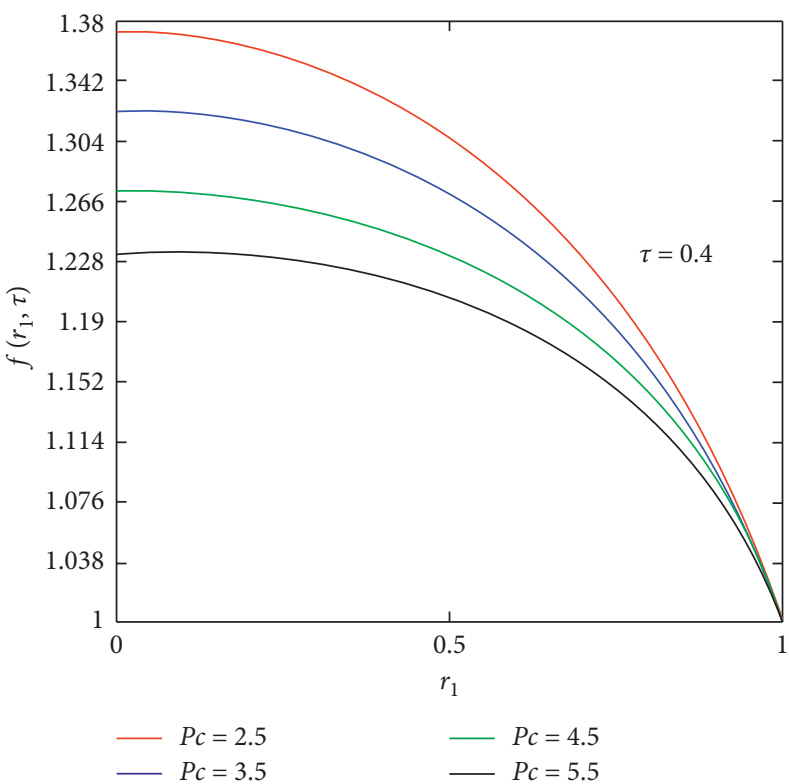

(a)

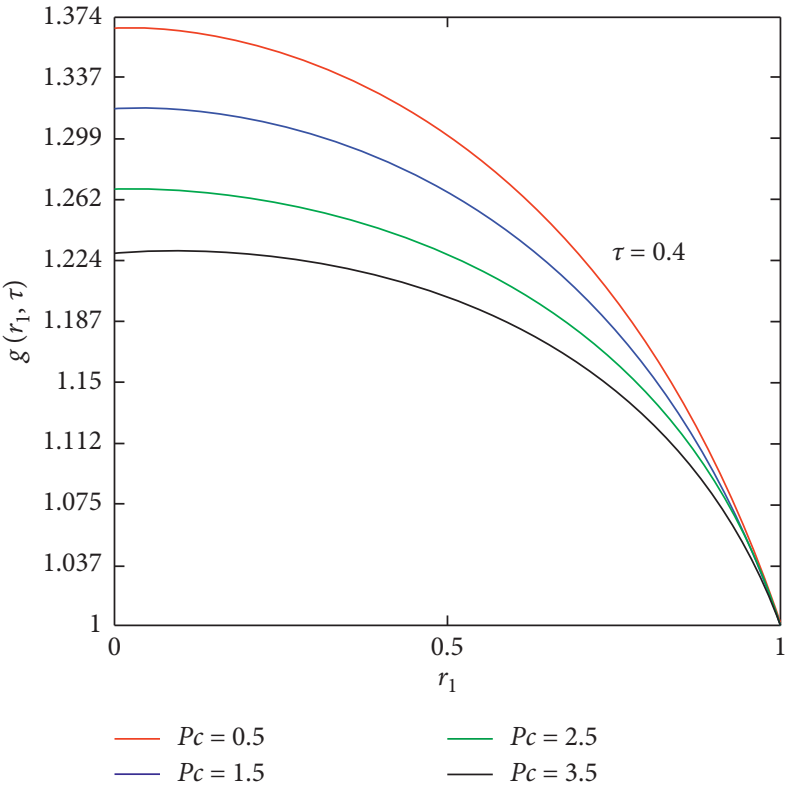

(b)

Figure 8: Variation in blood and magnetic particles profile against $r_{1}$ due to variation in $P_{c}$ for a short time when $\alpha=0.5, \beta=0.5, A_{0}=0.5, A_{1}=0.6, P_{m}=0.8, \omega t=(5 \pi / 8), \operatorname{Pr}=22.64$, and $\mathrm{Gr}=3.2 \times 10^{2}$.

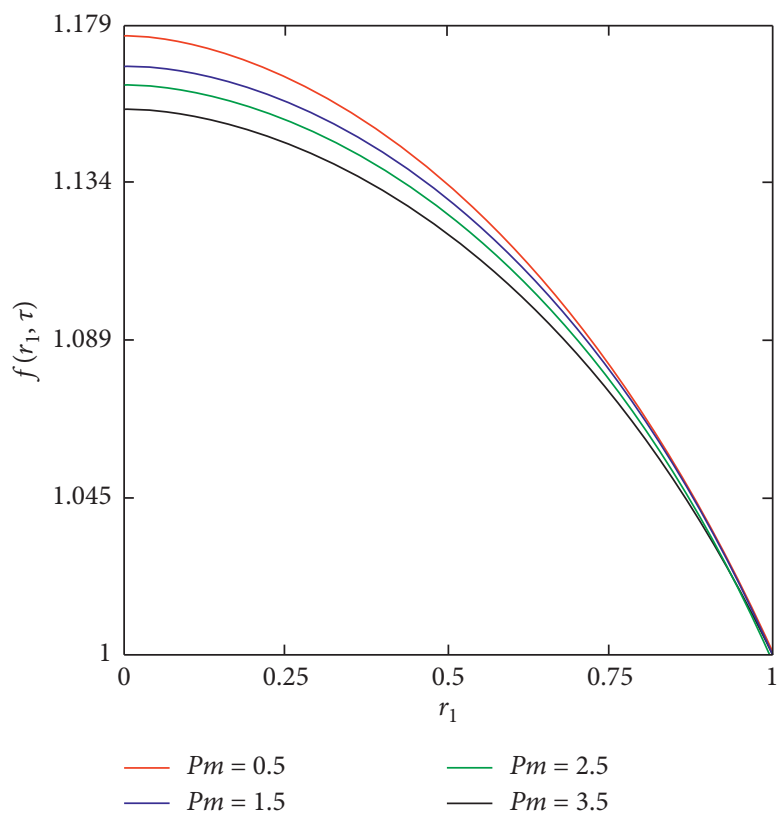

(a)

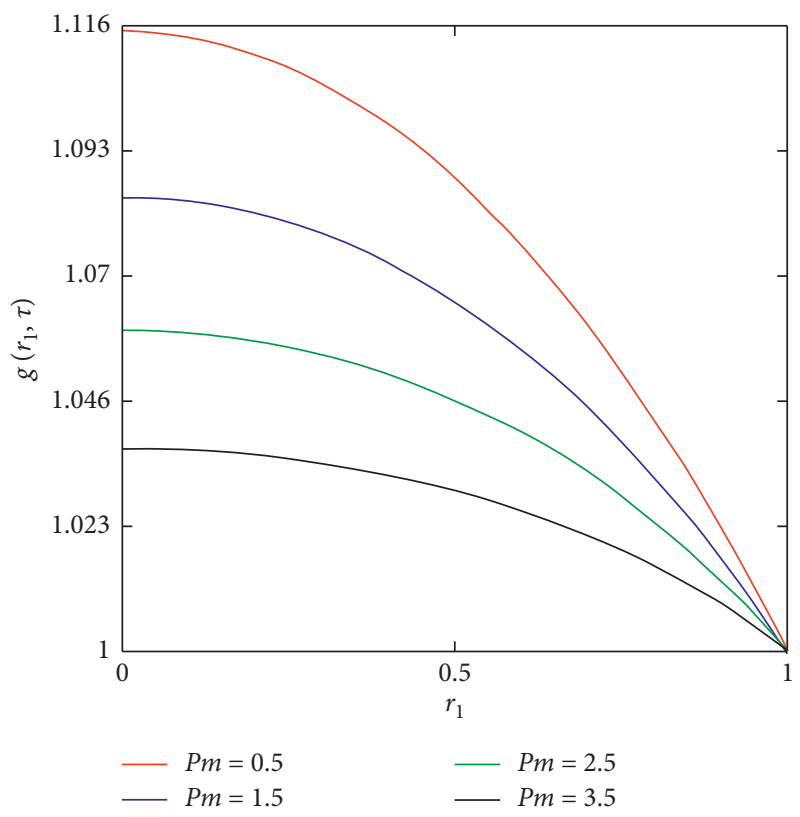

(b)

FIgURE 9: Variation in blood and magnetic particles profile against $r_{1}$ due to variation in the particle concentration parameter: $\alpha=0.5, \beta=0.5, A_{0}=0.5, A_{1}=0.6, P_{c}=0.8, \omega t=(5 \pi / 8), \operatorname{Pr}=22.64$, and $\mathrm{Gr}=3.2 \times 10^{2}$. 


\section{Conclusions}

In the present paper, we have considered Brinkman-type fluid in a heated cylindrical tube with MHD effects. Flow equation is modeled by using Caputo time-fractional derivative. Laplace and Hankel's transforms are employed to get the exact solutions to the problem. Furthermore, the impact of the different parameter on fluid temperature and velocity of blood and particles are discussed in detail. The present investigation plays a significant role in the study of blood flow in presence of magnetic field. Some of the useful findings are listed below:

For long time, increase in the fractional parameter, a reduction in the fluid and particle velocity has been observed, while for short time, reverse behavior has been observed.

A decrease in velocity of blood and magnetic particles has been observed for larger value of the magnetic number, which implies blood flow can be controlled by using magnetic field.

Retardation in velocity distribution of fluid and particles have been noticed when the Brinkman parameter is increased.

Increasing the values of concentration parameter causes a decrease in fluid and particles' velocity

A decrease in both the velocities of blood and particles has been observed for rising values of particle mass parameter. It is true because from the law of inertia if the applied forces are kept constant, then the increasing mass of particles slows down the motion of the subject fluid.

\section{Nomenclature}

$\begin{array}{ll}{ }_{-} T_{\infty}: & \text { Ambient temperature } \\ T_{w}: & \text { Surface temperature } \\ f: & \text { Dimensionless fluid velocity }\left(\mathrm{ms}^{-1}\right) \\ \vec{E}: & \text { Electric field intensity } \\ \vec{B}: & \text { Magnetic flux intensity } \\ k: & \text { Thermal conductivity of fluid }\left(\mathrm{Wm}^{-1} \mathrm{~K}^{-1}\right) \\ \mu_{0}: & \text { Magnetic permeability } \\ J: & \text { Electric current density } \\ \sigma: & \text { Electrical conductivity }\left(\mathrm{s}^{3} \mathrm{~A}^{2} \mathrm{~m}^{-3} \mathrm{~kg}^{-1}\right) \\ B_{0}: & \text { Applied magnetic field } \\ g: & \text { Gravitational acceleration }\left(\mathrm{ms}^{-2}\right) \\ \beta_{T}: & \text { Thermal expansion coefficient }\left(K^{-1}\right) \\ m: & \text { Mass of magnetic particles }\left(\mathrm{kg}^{-1}\right) \\ p: & \text { Oscillating pressure gradient } \\ \alpha: & \text { Fractional parameter } \\ \mathrm{Pr}: & \text { Prandtl number } \\ \mathrm{Gr}: & \text { Grashof number } \\ t: & \text { Dimensional time } \\ \overrightarrow{\vec{V}}: & \text { Velocity field } \\ g\left(r_{1}, \tau\right): & \text { Dimensionless particles' velocity }\left(\mathrm{ms} \mathrm{s}^{-1}\right) \\ \lambda_{0}: & \text { Amplitude of systolic pressure gradient } \\ \lambda_{1}: & \text { Amplitude of diastolic pressure gradient } \\ \mu: & \text { Dynamic viscosity of fluid }\left(\mathrm{kgm}^{-1} \mathrm{~s}^{-1}\right) \\ & \end{array}$

$\begin{array}{ll}u(r, t): & \text { Blood velocity }\left(\mathrm{ms}^{-1}\right) \\ \rho: & \text { Density of fluid }\left(\mathrm{kgm}^{-3}\right) \\ v: & \text { Kinematic viscosity }\left(\mathrm{m}^{2} \mathrm{~s}^{-1}\right) \\ K: & \text { Stokes' constant } \\ \beta: & \text { Brinkman-type fluid parameter } \\ N: & \text { Number of magnetic particles } \\ u_{p}: & \text { Velocity of magnetic particles }\left(\mathrm{ms}^{-1}\right) \\ u: & \text { Velocity of fluid }\left(\mathrm{ms}^{-1}\right) \\ T: & \text { Temperature field }(K) \\ r: & \text { Radial axis } \\ M: & \text { Magnetic parameter } \\ C_{p}: & \text { Specific heat capacity }\left(\mathrm{m}^{2} \mathrm{~K}^{-1} \mathrm{~s}^{2}\right) .\end{array}$

\section{Data Availability}

All the data used to support the findings of the study are available within the article.

\section{Conflicts of Interest}

The authors declare that they have no conflicts of interest.

\section{References}

[1] J. M.-R. Carlton, C. A. Yowell, K. A. Sturrock, and J. B. Dame, "Biomagnetic separation of contaminating host leukocytes from plasmodium-infected erythrocytes," Experimental Parasitology, vol. 97, no. 2, pp. 111-114, 2001.

[2] A. Zeeshan, N. Ijaz, T. Abbas, and R. Ellahi, "The sustainable characteristic of bio-bi-phase flow of peristaltic transport of MHD Jeffrey fluid in the human body," Sustainability, vol. 10, no. 8 , p. $2671,2018$.

[3] F. Hussain, R. Ellahi, A. Zeeshan, and K. Vafai, "Modelling study on heated couple stress fluid peristaltically conveying gold nanoparticles through coaxial tubes: a remedy for gland tumors and arthritis," Journal of Molecular Liquids, vol. 268, pp. 149-155, 2018.

[4] E. E. Tzirtzilakis and V. C. Loukopoulos, "Biofluid flow in a channel under the action of a uniform localized magnetic field," Computational Mechanics, vol. 36, no. 5, pp. 360-374, 2005.

[5] M. W. Freeman, A. Arrott, and J. H. L. Watson, "Magnetism in medicine," Journal of Applied Physics, vol. 31, no. 5, pp. 404-405, 1960.

[6] J. Liu, G. A. Flores, and R. Sheng, "In-vitro investigation of blood embolization in cancer treatment using magnetorheological fluids," Journal of Magnetism and Magnetic Materials, vol. 225, no. 1-2, pp. 209-217, 2001.

[7] E. K. Ruuge and A. N. Rusetski, "Magnetic fluids as drug carriers: targeted transport of drugs by a magnetic field," Journal of Magnetism and Magnetic Materials, vol. 122, no. 1-3, pp. 335-339, 1993.

[8] W. Boyd, Text-book of Pathology; Structure and Function in Diseases, Henry Kimpton, London, UK, 1970.

[9] S. Sharma, U. Singh, and V. K. Katiyar, "Magnetic field effect on flow parameters of blood along with magnetic particles in a cylindrical tube," Journal of Magnetism and Magnetic Materials, vol. 377, pp. 395-401, 2015.

[10] Y. Haik, V. Pai, and C. J. Chen, "Development of magnetic device for cell separation," Journal of Magnetism and Magnetic Materials, vol. 194, no. 1-3, pp. 254-261, 1999. 
[11] N. F. Borrelli, A. A. Luderer, and J. N. Panzarino, "Hysteresis heating for the treatment of tumours," Physics in Medicine and Biology, vol. 29, no. 5, pp. 487-494, 1984.

[12] J. Wang, Y. Huang, A. E. David et al., "Magnetic nanoparticles for MRI of brain tumors," Current Pharmaceutical Biotechnology, vol. 13, no. 12, pp. 2403-2416, 2012.

[13] S. C. McBain, H. H. Yiu, and J. Dobson, "Magnetic nanoparticles for gene and drug delivery," International Journal of Nanomedicine, vol. 3, no. 2, pp. 169-80, 2008.

[14] E. E. Tzirtzilakis, "A mathematical model for blood flow in magnetic field," Physics of Fluids, vol. 17, no. 7, Article ID 077103, 2005.

[15] S. E. Ghasemi, M. Hatami, A. K. Sarokolaie, and D. D. Ganji, "Study on blood flow containing nanoparticles through porous arteries in presence of magnetic field using analytical methods," Physica E: Low-Dimensional Systems and Nanostructures, vol. 70, pp. 146-156, 2015.

[16] R. Ellahi, R. S.U., and S. Nadeem, "The blood flow of prandtl fluid through a tapered stenosed arteries in permeable walls with magnetic field," Communications in Theoretical Physics, vol. 63, no. 3, pp. 353-358, 2015.

[17] M. M. Bhatti, A. Zeeshan, and R. Ellahi, "Endoscope analysis on peristaltic blood flow of Sisko fluid with Titanium magneto-nanoparticles," Computers in Biology and Medicine, vol. 78, pp. 29-41, 2016.

[18] A. Sinha and G. C. Shit, "Electromagnetohydrodynamic flow of blood and heat transfer in a capillary with thermal radiation," Journal of Magnetism and Magnetic Materials, vol. 378, pp. 143-151, 2015.

[19] A. Khan, A. Saeed, T. Gul, S. Mukhtar, I. Ali, and M. Jawad, "Radiative swirl motion of hydromagnetic Casson nanofluid flow over rotary cylinder using joule dissipation impact," Physica Scripta, vol. 96, no. 4, Article ID 045206, 2021.

[20] T. Gul, R. Akbar, Z. Zaheer, and I. S. Amiri, "The impact of the Marangoni convection and magnetic field versus blood-based carbon nanotube nanofluids," Proceedings of the Institution of Mechanical Engineers, Part N: Journal of Nanomaterials, Nanoengineering and Nanosystems, vol. 234, no. 1-2, pp. 3746, 2020.

[21] A. S. Dogonchi, M. A. Sheremet, I. Pop, and D. D. Ganji, "MHD natural convection of $\mathrm{Cu} / \mathrm{H}_{2} \mathrm{O}$ nanofluid in a horizontal semi-cylinder with a local triangular heater," International Journal of Numerical Methods for Heat \& Fluid Flow, vol. 28 , no. 12, 2018.

[22] S. M. Zokri, N. S. Arifin, M. K. A. Mohamed, A. R. M. Kasim, N. F. Mohammad, and M. Z. Salleh, "Influence of viscous dissipation on the flow and heat transfer of a Jeffrey fluid towards horizontal circular cylinder with free convection: a numerical study," Malaysian Journal of Fundamental and Applied Sciences, vol. 14, no. 1, pp. 40-47, 2018.

[23] A. Rahbari, M. Abbasi, I. Rahimipetroudi, B. Sundén, D. Domiri Ganji, and M. Gholami, "Heat transfer and MHD flow of non-Newtonian Maxwell fluid through a parallel plate channel: analytical and numerical solution," Mechanical Sciences, vol. 9, no. 1, pp. 61-70, 2018.

[24] J. Prakash and A. Ogulu, "A study of pulsatile blood flow modeled as a power law fluid in a constricted tube," International Communications in Heat and Mass Transfer, vol. 34, no. 6, pp. 762-768, 2007.

[25] N. S. Akbar, "Mixed convection analysis for blood flow through arteries on Williamson fluid model," International Journal of Biomathematics, vol. 8, no. 4, Article ID 1550045, 2015.
[26] H. C. Brinkman, "A calculation of the viscous force exerted by a flowing fluid on a dense swarm of particles," Flow, Turbulence and Combustion, vol. 1, no. 1, p. 27, 1949.

[27] K. Khanafer, K. Cook, and A. Marafie, "The role of porous media in modeling fluid flow within hollow fiber membranes of the total artificial lung," Journal of Porous Media, vol. 15, no. 2, pp. 113-122, 2012.

[28] A. A. Hill, "Convection induced by the selective absorption of radiation for the Brinkman model," Continuum Mechanics and Thermodynamics, vol. 16, no. 1, pp. 43-52, 2004.

[29] H. C. Brinkman, "On the permeability of media consisting of closely packed porous particles," Flow, Turbulence and Combustion, vol. 1, no. 1, p. 81, 1949.

[30] F. Ali, I. Khan, and S. Shae, "A note on new exact solutions for some unsteady flows of brinkman-type fluids over a plane wall," Zeitschrift Fr Naturforschung A, vol. 67, no. 6-7, pp. 377-380, 2012.

[31] C. Fetecau, C. Fetecau, and M. A. Imran, "On Stokes problem for fluids of Brinkman type," Reports on Mathematical Physics, vol. 13, no. 63, pp. 15-26, 2011.

[32] T. Anwar, P. Kumam, P. Thounthong, and K. Sitthithakerngkiet, "Nanoparticles shape effects on thermal performance of Brinkman-type ferrofluid under heat injection/consumption and thermal radiation: a fractional model with non-singular kernel and non-uniform temperature and velocity conditions," Journal of Molecular Liquids, vol. 335, Article ID 116107, 2021.

[33] M. Saqib, I. Khan, and S. Shafie, "Generalized magnetic blood flow in a cylindrical tube with magnetite dusty particles," Journal of Magnetism and Magnetic Materials, vol. 484, pp. 490-496, 2019.

[34] A. Kumar, R. Singh, G. S. Seth, and R. Tripathi, "Double diffusive magnetohydrodynamic natural convection flow of brinkman type nanofluid with diffusion-thermo and chemical reaction effects," Journal of Nanofluids, vol. 7, no. 2, pp. 338-349, 2018.

[35] R. Hilfer, P. L. Butzer, and U. Westphal, "An introduction to fractional calculus," Applications of Fractional Calculus in Physics, vol. 16, pp. 1-85, 2010.

[36] M. Du, Z. Wang, and H. Hu, "Measuring memory with the order of fractional derivative," Scientific Reports, vol. 3, no. 1, pp. 1-3, 2013.

[37] V. E. Tarasov and S. S. Tarasova, "Fractional derivatives and integrals: what are they needed for?" Mathematics, vol. 8, no. 2, p. 164, 2020.

[38] V. V. Kulish and J. L. Lage, "Application of fractional calculus to fluid mechanics," Journal of Fluids Engineering, vol. 124, no. 3, pp. 803-806, 2002.

[39] C. Ionescu, A. Lopes, D. Copot, J. A. T. Machado, and J. H. T. Bates, "The role of fractional calculus in modeling biological phenomena: a review," Communications in Nonlinear Science and Numerical Simulation, vol. 51, pp. 141-159, 2017.

[40] H. I. M. Singha and S. Sengupta, "Dusty time fractional MHD flow of a Newtonian fluid through a cylindrical tube with a non-Darcian porous medium," Journal of Applied Mathematics and Computational Mechanics, vol. 19, no. 4, pp. 101-114, 2020.

[41] H. Hong and M. Liang, "A fractional calculus technique for on-line detection of oil debris," Measurement Science and Technology, vol. 19, no. 5, Article ID 055703, 2008.

[42] L. Debnath, "Recent applications of fractional calculus to science and engineering," International Journal of 
Mathematics and Mathematical Sciences, vol. 2003, no. 54, pp. 3413-3442, 2003.

[43] I. Tejado, E. Pérez, and D. Valério, "Fractional calculus in economic growth modelling of the group of seven," Fractional Calculus and Applied Analysis, vol. 22, no. 1, pp. 139-157, 2019.

[44] A. Imtiaz, O.-M. Foong, A. Aamina, N. Khan, F. Ali, and I. Khan, "Generalized model of blood flow in a vertical tube with suspension of gold nanomaterials: applications in the cancer therapy," Computers, Materials \& Continua, vol. 65, no. 1, pp. 171-192, 2020.

[45] V. K. Sud and G. S. Sekhon, "Blood flow through the human arterial system in the presence of a steady magnetic field," Physics in Medicine and Biology, vol. 34, no. 7, pp. 795-805, 1989.

[46] M. Ahmad, M. A. Imran, M. Aleem, and I. Khan, "A comparative study and analysis of natural convection flow of MHD non-Newtonian fluid in the presence of heat source and first-order chemical reaction," Journal of Thermal Analysis and Calorimetry, vol. 137, no. 5, pp. 1783-1796, 2019.

[47] M. Asjad, "Fractional mechanism with power law (singular) and exponential (non-singular) kernels and its applications in bio heat transfer model," International Journal of Heat and Technology, vol. 37, no. 3, pp. 846-852, 2019.

[48] A. R. Butt, M. Abdullah, N. Raza, and M. A. Imran, "Influence of non-integer order parameter and Hartmann number on the heat and mass transfer flow of a Jeffery fluid over an oscillating vertical plate via Caputo-Fabrizio time fractional derivatives," The European Physical Journal Plus, vol. 132, no. 10, pp. 1-16, 2017.

[49] M. Sheikholeslami, M. Shamlooei, and R. Moradi, "Fe 3 O 4 -Ethylene glycol nanofluid forced convection inside a porous enclosure in existence of Coulomb force," Journal of Molecular Liquids, vol. 249, pp. 429-437, 2018.

[50] M. Sheikholeslami and D. D. Ganji, External Magnetic Field Effects on Hydrothermal Treatment of Nanofluid: Numerical and Analytical Studies, William Andrew, Norwich, NY, USA, 2016.

[51] M. Abdullah, A. R. Butt, N. Raza, A. S. Alshomrani, and A. K. Alzahrani, "Analysis of blood flow with nanoparticles induced by uniform magnetic field through a circular cylinder with fractional Caputo derivatives," Journal of Magnetism and Magnetic Materials, vol. 446, pp. 28-36, 2018.

[52] M. Sheikholeslami and H. B. Rokni, "Numerical simulation for impact of Coulomb force on nanofluid heat transfer in a porous enclosure in presence of thermal radiation," International Journal of Heat and Mass Transfer, vol. 118, pp. 823-831, 2018.

[53] K. R. Rajagopal, "On a hierarchy of approximate models for flows of incompressible fluids through porous solids," Mathematical Models and Methods in Applied Sciences, vol. 17, no. 02, pp. 215-252, 2007.

[54] P. K. Mandal, "An unsteady analysis of non-Newtonian blood flow through tapered arteries with a stenosis," International Journal of Non-linear Mechanics, vol. 40, no. 1, pp. 151-164, 2005.

[55] S. Uddin, M. Mohamad, K. Khalid et al., "Blood flow problem in the presence of magnetic particles through a circular cylinder using Caputo-Fabrizio fractional derivative," Journal of Physics: Conference Series, vol. 995, no. 1, Article ID 012007, 2018.

[56] M. Caputo, Elasticità e Dissipazione, Zanichelli, Bologna, Itlay, 1969.
[57] C. F. Lorenzo and T. T. Hartley, "Generalized functions for the fractional calculus," Critical Reviews ${ }^{\mathrm{TM}}$ in Biomedical Engineering, vol. 36, no. 1, pp. 39-55, 1999.

[58] N. Ali Shah, D. Vieru, and C. Fetecau, "Effects of the fractional order and magnetic field on the blood flow in cylindrical domains," Journal of Magnetism and Magnetic Materials, vol. 409, pp. 10-19, 2016.

[59] F. Ali, A. Imtiaz, I. Khan, and N. A. Sheikh, "Flow of magnetic particles in blood with isothermal heating: a fractional model for two-phase flow," Journal of Magnetism and Magnetic Materials, vol. 456, pp. 413-422, 2018.

[60] R. Nandkeolyar and M. Das, "Unsteady MHD free convection flow of a heat absorbing dusty fluid past a flat plate with ramped wall temperature," Afrika Matematika, vol. 25, no. 3, pp. 779-798, 2014. 